\title{
Efektivitas Strategi PBL Berbasis Potensi Akademik Terhadap Keterampilan Pemecahan Masalah dan Berpikir Kritis Siswa SMA Pada Topik Lingkungan
}

\author{
${ }^{1}$ I. W Karmana, ${ }^{2}$ I.D Dharmawibawa, ${ }^{3}$ T.L. Hajiriah \\ ${ }^{1,2,3}$ Prodi Pendidikan Biologi, FSTT, Universitas Pendidikan Mandalika \\ Email: wayankarmana@ikipmataram.ac.id
}

\begin{abstract}
The purpose of this research is to explain the effect of Problem Based Learning (PBL) and academic potential and their interactions toward problem solving and critical thinking skills of high school students. This research is a quasi-experiment that implements two different strategies with pretest-posttest non equivalent control group design by treatment factorial $2 \times 2$ which was conducted in the 2018/2019 academic year. Population of this research was class X students of SMA Negeri 8 Mataram, while the research sample was class X students of 2 classes with a purposive sampling technique. Research instruments is test of problem solving skills and test of critical thinking skills. Data analysis was performed with descriptive analysis and to test the hypothesis an anacova test was followed by further test used of Least Significant Difference (LSD). The calculation is aided by the SPSS 14 for Windows program. The results of this research showed that Problem Based Learning affects the problem solving and critical thinking skills. While academic ability (potential) and interaction of learning strategies with academic potential do not affect the problem solving and critical thinking skills of high school students on enviromental topic.
\end{abstract}

Abstrak. Tujuan penelitian ini adalah untuk menjelaskan pengaruh Problem Based Learning $(P B L)$ dan potensi akademik serta interaksinya terhadap keterampilan pemecahan masalah dan berpikir kritis siswa SMA. Jenis penelitian ini adalah quasi eksperimen yang mengimplementasikan dua strategi berbeda dengan rancangan pretest-posttest non equivalent control group design faktorial 2x2 yang dilaksanakan pada Tahun Pelajaran 2018/2019. Populasi penelitian adalah siswa kelas X SMA Negeri 8 Mataram, sedangkan sampel penelitian adalah siswa kelas $\mathrm{X}$ sebanyak 2 kelas dengan teknik purposive sampling. Instrumen penelitian berupa tes keterampilan pemecahan masalah dan tes keterampilan berpikir kritis. Analisis data dilakukan dengan analisis deskriptif dan untuk menguji hipotesis dilakukan uji anakova yang dilanjutkan uji lanjut Least Significant Difference (LSD). Penghitungan dibantu dengan program SPSS 14 for Windows. Hasil penelitian menunjukkan bahwa Problem Based Learning berpengaruh efektif terhadap keterampilan pemecahan masalah dan berpikir kritis. Sementara kemampuan (potensi) akademik dan interaksi strategi pembelajaran dengan potensi akademik tidak berpengaruh efektif terhadap keterampilan pemecahan masalah dan berpikir kritis siswa SMA pada topik lingkungan..

Kata kunci: PBL, Potensi Akademik, Pemecahan Masalah, Berpikir Kritis

\section{PENDAHULUAN}

Keterampilan pemecahan masalah dan berpikir kritis merupakan keterampilan esensial yang harus dimiliki pebelajar pada abad 21 (Partnership21 $^{\text {st }}$ Century Skills, 2011). Hal itu juga dikatakan Wasis (2016) bahwa keterampilan berpikir tingkat tinggi diantaranya keterampilan penyelesaian masalah dan keterampilan berpikir ktritis sudah selayaknya menjadi fokus pengembangan pembelajaran di Indonesia, karena diyakini potensial menjadikan seseorang memiliki kecakapan hidup, kreasi, inovasi, sehingga mampu menyelesaikan berbagai permasalahan hidup yang semakin kompleks di era globalisasi abad 21 ini.

Menurut Dwiyogo (2008) ada tujuh keterampilan yang diperlukan untuk dapat menjadi pribadi yang mandiri pada abad ini, antara lain yaitu keterampilan berpikir dan berbuat secara kritis, termasuk di dalamnya mampu memecahkan masalah, melakukan 
penyelidikan, melakukan analisis dan mengelola proyek. Berdasarkan pendapat tersebut dapat dikatakan tujuan pendidikan saat ini berupaya memberdayakan kemampuan berpikir tingkat tinggi (higher order thinking) seperti berpikir kritis, berpikir kreatif, memecahkan masalah, mengambil keputusan, keterampilan metakognisi dan lainnya.

Dharma (2008) juga mengatakan bahwa keterampilan berpikir kritis dan kreatif (critical and creative thinking skill) merupakan salah satu tuntutan pendidikan abad 21 yang ditandai dengan kompetisi global. Ini berarti bahwa pendidikan nasional diharapkan mampu menghasilkan manusia Indonesia yang cerdas untuk mengembangkan potensi dan karakter siswa, sehingga memiliki kemampuan memecahkan masalah hidup yang dihadapi serta dapat membentuk manusia yang mampu berpikir kritis, kreatif, dan inovatif (Sanjaya, 2011).

Sejalan dengan tuntutan pendidikan tersebut dalam kurikulum 2013, khususnya dalam standar proses disarankan agar dalam pembelajaran lebih menggunakan dan memperkuat pendekatan saintifik (ilmiah), mengimplementasikan pembelajaran pengungkapan/penelitian (discovery/inquairy) dan mendorong menggunakan pembelajaran berbasis pemecahan masalah berupa project based learning ataupun problem based learning (Permendikbud Nomor 22 Tahun 2016).

Fenomena-fenomena dilapangan khususnya di SMA Negeri 8 Mataram, dimana dari hasil observasi dan wawancara diperoleh informasi bahwa pembelajaran di SMA tersebut masih cukup dominan berorientasi teacher centered, belum pernah menerapkan Problem Based Learning. Diperoleh juga informasi secara kualitatif keterampilan pemecahan masalah dan berpikir kritis, dan hasil belajar siswa relatif masih rendah. Selain itu belum pernah mengukur kemampuan pemecahan masalah dan berpikir kritis secara khusus terutama dalam pembelajaran biologi pada semua tingkatan kelas.
Proses pembelajaran selama ini belum banyak memberdayakan potensi siswa sebagaimana amanat tujuan pendidikan nasional. Kemampuan akademik yang berbeda di kelas belum diperhatikan oleh guru. Strategi pembelajaran yang diterapkan belum mengakomodasi seluruh karakter kemampuan akademik siswa, sehingga jarak antara siswa berkemampuan tinggi dan rendah masih tetap jauh dalam hal keterampilan penyelesaian masalah dan berpikir kritis yang merupakan suatu keterampilan berpikir tingkat tinggi.

Salah satu solusi untuk mengatasi permasalahan tersebut adalah dengan penerapan Problem Based Learning dalam pembelajaran biologi. Pembelajaran berbasis masalah adalah suatu pendekatan pengajaran yang menggunakan masalah dunia nyata sebagai suatu konteks bagi siswa untuk belajar tentang cara berpikir kritis dan keterampilan pemecahan masalah, serta untuk memperoleh pengetahuan dan konsep yang esensial dari materi pelajaran, melatih berpikir tingkat tinggi termasuk di dalamnya belajar bagaimana belajar (metakognif) dan melatih siswa menjadi pebelajar mandiri dan self regulated (Arends, 2008). Sementara itu Nugraheni (2007) menyatakan untuk meningkatkan kemampuan berpikir kritis siswa adalah melalui $P B L$. Sementara Trianto (2007) menyatakan pembelajaran berbasis masalah merupakan pendekatan yang efektif untuk meningkatkan kemampuan berpikir kritis pada siswa dan cocok untuk bidang ilmu seperti IPA (biologi) dan matematika. Tessier (2004) juga menyatakan bahwa di kelas sains (IPA) pembelajaran berbasis masalah menjadi suatu pendekatan yang populer dan efektif terutama bidang biologi yang menyangkut masalah lingkungan dan ekologi.

\begin{tabular}{llr}
\multicolumn{2}{c}{ Pernyataan-pernyataan } & tersebut \\
diperkuat oleh hasil-hasil penelitian \\
sebelumnya yang menerapkan $P B L$
\end{tabular} menunjukkan peningkatan pemahaman konsep, keterampilan pemecahan masalah dan berpikir kritis pada mata pelajaran biologi, fisika, dan matematika, ( Arnyana, 2008; Marpaung, 2005; dan Paidi, 2008; Solang, 
2008 ). Dwiyogo (2008) juga menyatakan penelitian mengenai $P B L$ mengkonfirmasi bahwa siswa mengembangkan keterampilan yang meliputi: (1) problem solving, (2) critical thinking, (3) research, (4) presentation, dan (5) moving vision to action. Oleh karena itu diperlukan penerapan strategi $P B L$ oleh guru sebagai salah satu alternatif dalam pembelajaran biologi untuk meningkatkan keterampilan pemecahan masalah dan berpikir kritis (Karmana, 2009). Terkait dengan hal tersebut, maka tujuan dari penelitian ini adalah (1) menjelaskan pengaruh Problem Based Learning terhadap keterampilan pemecahan masalah dan berpikir kritis, (2) menjelaskan potensi akademik terhadap keterampilan pemecahan masalah dan berpikir kritis, dan (3) menjelaskan interaksi Problem Based Learning dan potensi akademik terhadap keterampilan pemecahan masalah dan berpikir kritis siswa SMA 8 Mataram dalam pembelajaran biologi khususnya materi ekosistem.

\section{METODE PENELITIAN}

Jenis Penelitian ini adalah quasi eksperimen dengan rancangan pretest-posttest non equivalent control group design menggunakan faktorial $2 \mathrm{x}$ 2. Sampel penelitian adalah siswa kelas $\mathrm{X}$ SMAN 8 Mataram sebanyak 80 siswa (2 kelas) yang ditentukan secara purposive sampling. Dari dua kelas yang terpilih kemudian ditentukan secara random satu kelas sebagai kelas kontrol menggunakan strategi konvensional dan satu kelas sebagai kelas eksperimen, menggunakan strategi $P B L$.

Perangkat pembelajaran yang dirancang berupa silabus, skenario pembelajaran (RPP), dan LKS. Instrumen penelitian berupa tes keterampilan pemecahan masalah, tes keterampilan berpikir kritis. Analisis data menggunakan analisis deskriptif dan untuk uji hipotesis dilakukan uji statistik anakova yang dilanjutkan uji Least Significant Difference (LSD) pada taraf signifikansi $5 \%(\mathrm{p}<0,05)$ dengan bantuan SPSS14 for Windows. Dimana sebelum uji hipotesis terlebih dahulu dilakukan uji asumsi (persyaratan) berupa uji normalitas dan homogenitas data hasil penelitian.

\section{HASIL DAN PEMBAHASAN}

Berdasarkan hasil penelitian diperoleh data mengenai keterampilan pemecahan masalah dan berpikir kritis siswa dalam pembelajaran biologi siswa kelas X SMA 8 Mataram sebagai berikut.

\begin{tabular}{|c|l|c|l|c|c|}
\hline N & Variabel Pembelajaran & Pretes & Kategori & Posttest & Kategori \\
\hline 0 & & & & & \\
\hline 1. & PBL & 38,25 & Kurang & 45,63 & Sedang \\
\hline 2. & Konvensional (K) & 37,81 & Kurang & 39,88 & Sedang \\
\hline 3. & Kemampuan Tinggi(KT) & 39,04 & Kurang & 45,75 & Sedang \\
\hline 4. & Kemampuan Rendah (KR) & 37,25 & Kurang & 43,13 & Sedang \\
5. & Interaksi PBL-KT & 39,25 & Kurang & 47,13 & Sedang \\
\hline 6. & Interaksi PBL-KR & 37,25 & Kurang & 44,13 & Sedang \\
\hline 7. & Interaksi K-KT & 38,75 & Kurang & 40,38 & Sedang \\
8. & Interaksi K-KR & 36,88 & Kurang & 39,38 & Kurang \\
& & & & & \\
\hline
\end{tabular}

Tabel 1 Rata-rata Skor Keterampilan Pemecahan Masalah Pretes dan Posttest

Tabel 2 Rata-rata Skor Keterampilan Berpikir Kritis Pretes dan Posttest

\begin{tabular}{|c|c|c|c|c|c|}
\hline $\begin{array}{l}\mathrm{N} \\
0\end{array}$ & Variabel Pembelajaran & Pretes & Kategori & Posttest & Kategori \\
\hline 1. & $P B L$ & 43,75 & Kurang & 60,10 & Cukup \\
\hline 2. & Konvensional (K) & 43.05 & Kurang & 47,40 & Kurang \\
\hline 3. & Kemampuan Tinggi & 51,10 & Kurang & 64,73 & Baik \\
\hline 4. & (KT) & 36,47 & Sangat & 49,10 & Kurang \\
\hline 5. & Kemampuan Rendah & 51,10 & Kurang & 68,00 & Baik \\
\hline 6. & (KR) & 36,40 & Kurang & 52,20 & Kurang \\
\hline 7. & Interaksi $P B L-\mathrm{KT}$ & 50,40 & Sangat & 55,60 & Cukup \\
\hline 8. & $\begin{array}{l}\text { Interaksi } P B L-\mathrm{KR} \\
\text { Interaksi K-KT } \\
\text { Interaksi K-KR }\end{array}$ & 35,70 & $\begin{array}{c}\text { Kurang } \\
\text { Kurang } \\
\text { Sangat } \\
\text { Kurang }\end{array}$ & 39,20 & $\begin{array}{l}\text { Sangat } \\
\text { Kurang }\end{array}$ \\
\hline
\end{tabular}

Selanjutnya ringkasan hasil uji hipotesis dengan menggunakan analisis anakova dengan bantuan SPSS 14 for Windows tertera pada Tabel 4.

Tabel 4 Ringkasan Hasil Uji Hipotesis ( $\mathrm{p}<$ $0,05)$

(C)

\begin{tabular}{|c|c|c|c|c|}
\hline No & Variabel Terikat & Pengaruh/Perlakuan & $\mathrm{Sig}$ & Keterangan \\
\hline 1 & $\begin{array}{l}\text { Keterampilan } \\
\text { Pemecahan Masalah }\end{array}$ & $\begin{array}{l}\text { Strategi Pembelajaran } \\
\text { Potensi Akademik } \\
\text { Interaksi Strategi } \\
\text { Pembelajaran dan } \\
\text { Potensi Akademik }\end{array}$ & $\begin{array}{l}0,00 \\
0,21 \\
0,34\end{array}$ & $\begin{array}{l}\text { Signifikan } \\
\text { Tidak } \\
\text { Signifikan } \\
\text { Tidak } \\
\text { Signifikan } \\
\end{array}$ \\
\hline 2 & $\begin{array}{l}\text { Keterampilan } \\
\text { Berpikir Kritis }\end{array}$ & $\begin{array}{l}\text { Strategi Pembelajaran } \\
\text { Potensi Akademik } \\
\text { Interaksi Strategi } \\
\text { Pembelajaran dan } \\
\text { Potensi Akademik }\end{array}$ & $\begin{array}{l}0,00 \\
0,69 \\
0,11\end{array}$ & $\begin{array}{l}\text { Signifikan } \\
\text { Tidak Sinifikan } \\
\text { Tidak } \\
\text { Signifikan }\end{array}$ \\
\hline
\end{tabular}

Tabel 5 Ringkasan Hasil Uji Lanjut Least Significant Difference $(\mathrm{p}<0,05)$

\begin{tabular}{|c|l|c|c|c|}
\hline No & Variabel Terikat & Perlakuan & Sig. & Keterangan \\
\hline \multirow{2}{*}{1} & $\begin{array}{l}\text { Keterampilan } \\
\text { Pemecahan } \\
\text { Masalah }\end{array}$ & PBL x Konvensional & 0,00 & Signifikan \\
\hline & & & \\
\hline 2 & $\begin{array}{l}\text { Keterampilan } \\
\text { Berpikir Kritis }\end{array}$ & PBL x Konvensional & 0,00 & Signifikan \\
\hline
\end{tabular}




\section{PEMBAHASAN}

Hasil penelitian ini menunjukkan bahwa pembelajaran biologi dengan strategi $P B L$ berpengaruh signifikan terhadap skor kemampuan pemecahan masalah. Ada perbedaan yang signifikan antara pembelajaran biologi dengan strategi $P B L$ dibandingkan pembelajaran biologi dengan strategi konvensional.. Rata-rata skor terkoreksi (mean) PBL lebih tinggi 13,40\% dibandingkan dengan rata-rata skor strategi konvensional. Hasil penelitian ini mendukung penelitian sebelumnya yang dilakukan Paidi (2008) yang melaporkan bahwa strategi $P B L$ yang dipadu dengan strategi metakognitif dapat meningkatkan kemampuan pemecahan masalah dalam pembelajaran biologi.

Temuan penelitian ini sesuai dengan pernyataan White (2000); Oakey (2000); Herreid (2000); Hastings (2001); Wheeler (2002), dan Tindangen (2008) yang pada prinsipnya menyatakan $P B L$ berperan dalam mengembangkan kemampuan berpikir dan pemecahan masalah. Meningkatnya kemampuan pemecahan masalah dengan strategi $P B L$ disebabkan karena karakteristik $P B L$ yang diimplementasikan dengan baik.

Potensi akademik tidak berpengaruh signifikan terhadap skor kemampuan pemecahan masalah. Hasil penelitian ini tidak mendukung teori yang disampaikan Ausubel (dalam Lohnan, 1996) yang menyatakan kemampuan akademik siswa berpengaruh terhadap perkembangan intelektual siswa dan kemampuannya dalam menerapkan berpikir tingkat tinggi (kemampuan berpikir kritis, memecahkan masalah, analisis, evaluasi, dan mencipta). Demikian juga tidak sesuai dengan yang disampaikan Edwards \& Bries (2000) yang mengemukakan bahwa siswa yang memiliki kemampuan akademik awal tinggi, pencapaian berpikir tingkat tingginya lebih baik daripada siswa yang memiliki kemampuan awal rendah.

Hasil penelitian ini juga menunjukkan bahwa interaksi strategi pembelajaran dan kemampuan akademik tidak berpengaruh signifikan terhadap skor kemampuan pemecahan masalah. Hasil uji lanjut juga menunjukkan semua interaksi (kombinasi) tidak ada perbedaan signifikan satu dengan yang lainnya.

Hasil penelitian ini menunjukkan pembelajaran biologi dengan strategi $P B L$ berpengaruh signifikan terhadap skor kemampuan berpikir kritis. Ada perbedaan yang signifikan antara pembelajaran biologi dengan strategi $P B L$ dibandingkan pembelajaran biologi dengan strategi konvensional.

Rata-rata skor terkoreksi (mean) $P B L$ lebih tinggi $27,43 \%$ dibandingkan dengan rata-rata skor strategi konvensional. Temuan penelitian ini mendukung penelitianpenelitian terkait sebelumnya yang dilakukan Marpaung (2005), dan Setiawan (2005). Semua penelitian tersebut menunjukkan pembelajaran dengan $P B L$ dapat meningkatkan kemampuan berpikir kritis siswa dalam pembelajaran biologi.

Meningkatnya kemampuan berpikir kritis siswa ini tidak terlepas dari karakteristik PBL seperti dinyatakan Arends (2008) bahwa $P B L$ menggunakan masalah dunia nyata sebagai konteks untuk belajar berpikir kritis. Demikian juga pernyataan Nugraheni (2007) dan Trianto (2007) bahwa $P B L$ dapat meningkatkan kemampuan berpikir kritis siswa secara efektif dan cocok untuk pelajaran IPA (biologi).

Hasil penelitian ini menemukan bahwa kemampuan berpikir kritis siswa tidak berbeda signifikan antara siswa berkemampuan akademik tinggi dan rendah. Temuan ini mendukung hasil penelitian sebelumnya yang dilakukan Setiawan (2005), Hadi (2007), dan Muhfahroyin (2009) yang menyimpulkan bahwa tidak ada perbedaan signifikan antara siswa berkemampuan akademik tinggi dan rendah terhadap kemampuan berpikir kritis dalam pembelajaran biologi. Namun hasil penelitian ini berbeda dengan temuan Winarni (2006), dan Indriwati (2007) yang melaporkan bahwa siswa yang berkemampuan akademik tinggi memperoleh skor kemampuan berpikir kritis yang lebih tinggi dibandingkan dengan siswa yang berkemampuan akademik rendah.

Sementara itu diperoleh hasil temuan bahwa interaksi strategi pembelajaran dan 
kemampuan akademik tidak berpengaruh signifikan terhadap skor kemampuan berpikir kritis. Hasil uji lanjut menunjukkan juga tidak berbeda signifikan antara kelompok kombinasi yang satu dengan yang lainnya.

\section{SIMPULAN}

Berdasarkan analisis data dan pembahasan hasil penelitian dapat dirumuskan simpulan sebagai berikut: (1) Problem Based Learning berpengaruh efektif terhadap skor kemampuan pemecahan masalah, kemampuan berpikir kritis. Pengaruh strategi $P B L$ lebih tinggi 13,40\%, dari strategi konvensional terhadap kemampuan pemecahan masalah. Sementara itu pengaruh strategi $P B L$ lebih tinggi $27,43 \%$, dari strategi konvensional terhadap kemampuan berpikir kritis, (2) kemampuan akademik tidak berpengaruh efektif terhadap skor kemampuan pemecahan masalah, kemampuan berpikir kritis, dan (3) interaksi strategi pembelajaran dan kemampuan akademik tidak berpengaruh efektif terhadap skor kemampuan pemecahan masalah, dan kemampuan berpikir kritis dalam pembelajaran biologi pada topik lingkungan.

\section{Saran}

Berdasarkan simpulan, maka disarankan agar guru mengimplementasikan strategi $P B L$ sebagai salah satu strategi dalam pembelajaran biologi khususnya topik lingkungan dalam meningkatkan kemampuan pemecahan masalah, dan kemampuan berpikir kritis. Selain itu diharapkan memberdayakan perbedaan kemampuan/potensi akademik dalam membentuk kelompok belajar siswa agar tercipta scaffolding, sehingga hasil belajar siswa dengan potensi akademik rendah mampu menyamai hasil belajar siswa dengan potensi akademik yang tinggi. Bagi peneliti selanjutnya dapat menindak lanjuti hasil penelitian ini untuk mengungkap hal-hal yang belum di teliti dari masalah yang terkait.

\section{DAFTAR RUJUKAN}

Arends, R. 2008. Learning To Teach (Belajar untuk Mengajar). Edisi Ketujuh, Buku II. Yogyakarta: Pustaka Pelajar.

Arnyana, I.B.P. 2006. Pengaruh Penerapan $\begin{array}{lrr}\text { Strategi } & \text { Pembelajaran } & \text { Inovatif } \\ \text { Terhadap } & \text { Kemampuan } & \text { Berpikir }\end{array}$
Kreatif Siswa SMA.Jurnal Pendidikan dan Pengajaran. 39 (3):496-515.

Dharma, S. 2008. Pembangunan Pendidik

Tenaga Kependidikan Menghadapi

Tantangan Abad 21. Makalah

Disajikan dalam Kuliah Umum Bagi

Mahasiswa Program Pascasarjana UM

Tahun Akademik 2008/2009. Malang:

27 Agustus.

Dwiyogo, W.D. 2008. Merancang Pembelajaran Problem Based Learning (Bahan Kuliah Landasan Pendidikan \& Pembelajaran). Malang: Program Pascasarjana Universitas Negeri Malang.

Edwards, M.C \& Bries, G.E. 2000. Higher Order and Lower Order Thinking Skill Achievement in Secondary-Level Animal Science. Does Block Shceduling Pattern Influence End-Of Course Learner Performance. Journal of Agricultural Education, 41(4):2-14.

Hadi, S. 2007. Pengaruh Strategi Pembelajaran Cooperative Script terhadap Keterampilan Berpikir Kritis, Keterampilan Metakognitif, dan Kemampuan Kognitif Biologi pada Siswa SMA Laboratorium Universitas Negeri Malang. Tesis tidak diterbitkan. Malang: Program Pascasarjana Universitas Negeri Malang.

Hastings, D. 2001. Case Study Problem Based Learning and the Active Classroom, (Online), (http://www.cstudies.ubc.ca/facdev/ser vices/newsletter/index/html, diakses 12 April 2009).

Herreid, C.F. 2000. AIDS and the Duesberg Phenomenon: A Problem Based Learning Case Study, (Online), (http://search

yahoo.com/search?p=problem+based+ learning, diakses 12 April 2009).

Indriwati, S. E. 2007. Pengaruh Strategi Pembelajaran dan Tingkat Kemampuan Akademik terhadap Hasil Belajar Kognitif dan Kecakapan Hidup Mahasiswa Biologi FMIPA UM. Disertasi tidak diterbitkan. 
Malang: Program Pascasarjana Universitas Negeri Malang.

Karmana, I. W. 2009. Meningkatkan Kemampuan Pemecahan Masalah dan Berpikir Kritis dalam Pembelajaran Biologi melalui Problem Based Learning. Ganec Swara, 3 (1): 33-38.

Lohnan, D.F. 1996. Intelligence, Learning, and Instruction. British: Pergamon $\mathrm{P}$ 660-664.

Marpaung, Rini Rita T. 2005. Penggunaan Lembar Kegiatan Berbasis Masalah (LKBM) Sebagai Assesmen Alternatif untuk Meningkatkan Kemampuan Berpikir Kritis dan Hasil Belajar Biologi Siswa Kelas VII SMP Laboratorium Universitas Negeri Malang. Tesis tidak diterbitkan. Malang: Program Pascasarjana Universitas Negeri Malang.

Muhfahroyin. 2009. Pengaruh Strategi Pembelajaran Integrasi STAD dan TPS dan Kemampuan Akademik Terhadap Hasil Belajar Kognitif Biologi, Kemampuan Berpikir Kritis, dan Keterampilan Proses Siswa SMA di Kota Metro Disertasi tidak diterbitkan. Malang: Program Pascasarjana Universitas Negeri Malang.

Nugraheni, E. 2007. Student Centered Learning dan Implikasinya terhadap Proses Pembelajaran. Jurnal Pendidikan, 8 (1): 1-10

Oakey, J. 2000. Project Based and Problem Based: The Same or Different?, (Online), (http://search yahoo.com/search?p=problem+based+ learning, diakses 12 April 2009).

Paidi. 2008. Pengembangan Perangkat Pembelajaran Biologi Yang Mengimplementasikan PBL dan Strategi Metakognitif Serta Efektivitasnya Terhadap Kemampuan Metakognitif, Pemecahan Masalah, dan Penguasaan Konsep Biologi Siswa SMA di Sleman Yogyakarta. Disertasi tidak diterbitkan. Malang:
Program Pascasarjana Universitas Negeri Malang.

Peraturan Mendikbud No 22 Tahun 2016 tentang Standar Proses. Bandung: Penerbit Citra Umbara.

Rahman, S. \& John, A.P. 2006. Hubungan Antara Kesadaran Metakognisi, Motivasi, dan Pencapaian Akademik Pelajar Universiti. Jurnal Pendidikan, 31 (2) : 21-39.

Sanjaya, W. 2011. Strategi Pembelajaran: Berorientasi Standar Proses Pendidikan. Jakarta: Kencana Prenada Media.

Setiawan, I.G.N. 2005. Pengaruh Pembelajaran Kontekstual dalam Strategi Inkuiri dan Pembelajaran Berdasarkan Masalah untuk Meningkatkan Kemampuan Berpikir dan Penguasaan Konsep-Konsep Biologi Siswa SMP Di Kecamatan Buleleng Bali. Disertasi tidak diterbitkan. Malang: Program Pascasarjana Universitas Negeri Malang.

Solang, D. J. 2008. Latihan Keterampilan Intelektual dan Kemampuan Pemecahan Masalah Secara Kreatif. Jurnal Ilmu Pendidikan, 15 (1): 35-42.

Tessier, J.T. 2004. Ecological Problem Based Learning An Enviromental Consulting Task. The American Biology Teacher, 66(7):477-483.

Tindangen, M. 2006. Potret Pembelajaran, Masalah Kemampuan Berpikir, dan Alternatif Pendekatan Pembelajaran di SD. Jurnal Sekolah Dasar, 15 (2): 117-127.

Trianto. 2007. Model-model Pembelajaran Berorientasi Konstruktivistik (Konsep, Landasan Teoritis Praktis dan Implementasinya). Jakarta: Prestasi Pustaka Publisher.

Wang, H.C.A., Thompson, \& Shuller, C.F. 1998. Essential Components of Problem-Based Learning for the K-12 Inquary. Science Instruction, (Online), (http:// searchyahoo.com, diakses 27 Juli 2009). 
terakreditasi Peringkat 4 (No. SK: 36/E/KPT/2019)

Wheeler, S. 2002. Dual-ModeDelivery of Problem Based Learning A Constructivist Persfective, (Online), (http:// searchyahoo.com, diakses 27 Juli 2009).

White, H. 2007. Problem Based Learning in Introductory Science Across Disciplines, (Online), (http://www.udel.edu/chem/white/fina lrpt.html, diakses 16 Mei 2010).

Wardani, I.G.A.K. 2006. Berpikir Kritis dan Kreatif Terapannya dalam Pembelajaran. Jurnal Sekolah Dasar, 15 (2): 101-116. 